\title{
THE DETERMINATION METHOD AND RESOLVING PROCEDURE OF DESIGN CONFLICT BASED ON EVOLUTION PATTERN AND PREREQUISITE TREE
}

\author{
Lihui Ma,Runhua Tan \\ Hebei University of Technology, Tianjin,300130, China.Email: malh198@yahoo.com.cn
}

\begin{abstract}
In this paper, a determination model of design conflict based on the evolution theory of TRIZ and the Prerequisite Tree (PRT) is proposed. The evolution patterns are used to identify evolving objectives and the PRT is used to identify all evolving obstacles. A new conflict determining diagram and template are set up to identify design conflict. Then the separation principles or the conflict matrix in TRIZ are applied to solve the design conflicts. A case of engineering has verified the application of the process model.
\end{abstract}

Key words: TRIZ, PRT, design conflict or contradiction, evolution pattern

\section{INTRODUCTION}

The key of product innovation lies in finding and solving the conflict or contradiction in design. Conflict is basic to the definition of a technical problem in TRIZ. TRIZ (Theory of Inventive Problem Solving) is a method for solving inventive problems based on the knowledge where there is no obvious solution and where there is at least one major contradiction that appears to be irresolvable. TRIZ provides a wide-ranging series of techniques and tools for solving technical problems of various complexities, which can help designers and inventors to avoid trial-and-error approach in design process and to solve problem in creative and powerful ways ${ }^{1}$. However, TRIZ has not provided a method with stronger effectiveness to

Please use the following format when citing this chapter:

Ma, Lihui, Tan, Runhua, 2006, in International Federation for Information Processing (IFIP), Volume 207, Knowledge Enterprise: Intelligent Strategies In Product Design, Manufacturing, and Management, eds. K. Wang, Kovacs G., Wozny M., Fang M., (Boston: Springer), pp. 457-464. 
confirm the conflict of design ${ }^{2}$. How to confirm the design conflict has already become a focus of the research on TRIZ in recent years ${ }^{3-7}$. In some literatures ${ }^{8-10}$, TRIZ and Thinking Process from TOC are integrated to identify conflict. But just as Darrell MANN and Roy STRATTON stated in their thesis ${ }^{10}$ that the area of greatest common ground between CRD and TRIZ lies in the way in which CRD helps to define physical contradictions.

In this paper, a determining model of design conflict based on the evolution patterns of TRIZ and the Prerequisite Tree (PRT) of TOC (Theory of Constraints) is proposed, which can be applied to determine physical and technical conflicts. The synergy of TRIZ and Thinking Process will form the systemic process for identifying and solving design conflicts.

\section{CONTRADICTIONS IN DESIGN}

G.S.Alshuller divides contradictions into administrative contradictions, physical contradictions and technical contradictions ${ }^{7,11}$. Administrative contradictions don't belong to the contents of TRIZ.

Technical contradiction: an interaction between system's parts when the useful function/action causes simultaneously a harmful effect, or introduction (intensification) of the useful function/action, or elimination or reduction of the harmful function/action causes deterioration or unacceptable complication of one of the parts or of the whole system. Technical contradiction is usually shown as the conflict between two subsystems in a system.

Physical contradiction: a situation when the same component must satisfy mutually exclusive demands to its physical state, e.g., be hot and cold, electrically conductive and insulative, etc. For physical contradictions, there exist two opposing requests simultaneously on one aspect of the system.

\section{EVOLUTION PATTERNS AND PRT}

\subsection{Evolution patterns of TRIZ}

Evolution procedure of a product is a self-sustaining process that resolves the profound conflict constantly and pushes the product ever closer to its ideal state.

The TRIZ technology evolution developed by Altshuller ${ }^{12}$ is a set of patterns and paths, which show the trends of technological systems evolution in structures. 
The TRIZ technology evolution has different versions now ${ }^{7} . \mathrm{DE}^{13}$ is an important branch of the Evolution theory in TRIZ. The core of DE is the management and control of technical evolution process. DE has many patterns and paths, which are suitable for the innovation of technological system and production process. In this paper the patterns of DE are applied.

According to $\mathrm{DE}$, there are eight patterns of evolution as follows.

- Stages of evolutions.

- Increasing ideality.

- Uneven development of subsystems.

- Increasing dynamism and controllability.

- Increasing complexity, followed by simplicity.

- Matching and mismatching of parts.

- Transition toward micro-level and increasing use of fields.

- Decreasing human involvement.

\subsection{Prerequisite Tree (PRT) from TOC}

The Prerequisite Tree from TOC (Theory of Constraints) ${ }^{14}$ is a necessity based logic structure. Its purpose is to help us identify all obstacles and the intermediate steps (action, objective, or injection) that we need, to overcome them in realizing an objective.

\section{DETERMINATION METHOD AND RESOLVING PROCEDURE OF DESIGN CONFLICT}

Product design or development is the evolution process of overcoming contradictions constantly. Finding and determining conflict is the first step of innovation.

Identify the core problem (or root causes) is the key of the whole design process. PRT shows the designer how to identify all obstacles and the required sequence of actions needed to realize a desired course of action. TRIZ is strong in guiding designers how to identify objectives and solve the problems. It is very useful to integrate the Prerequisite Tree (PRT) from TOC and TRIZ for determining and resolving contradictions.

\subsection{Method to confirm conflict based on evolution patterns and PRT}

During the evolution of product, improvement of any part of the product, which can make the system reach its pinnacle of functional performance, 
will lead to conflict with another part of the product. Design of product is the process that overcomes the obstacle and resolves the corresponding conflict and pushes the product ever closer to its ideal state.

Figure 1 shows the determining procedure of contradictions, which includes 3 steps as below.

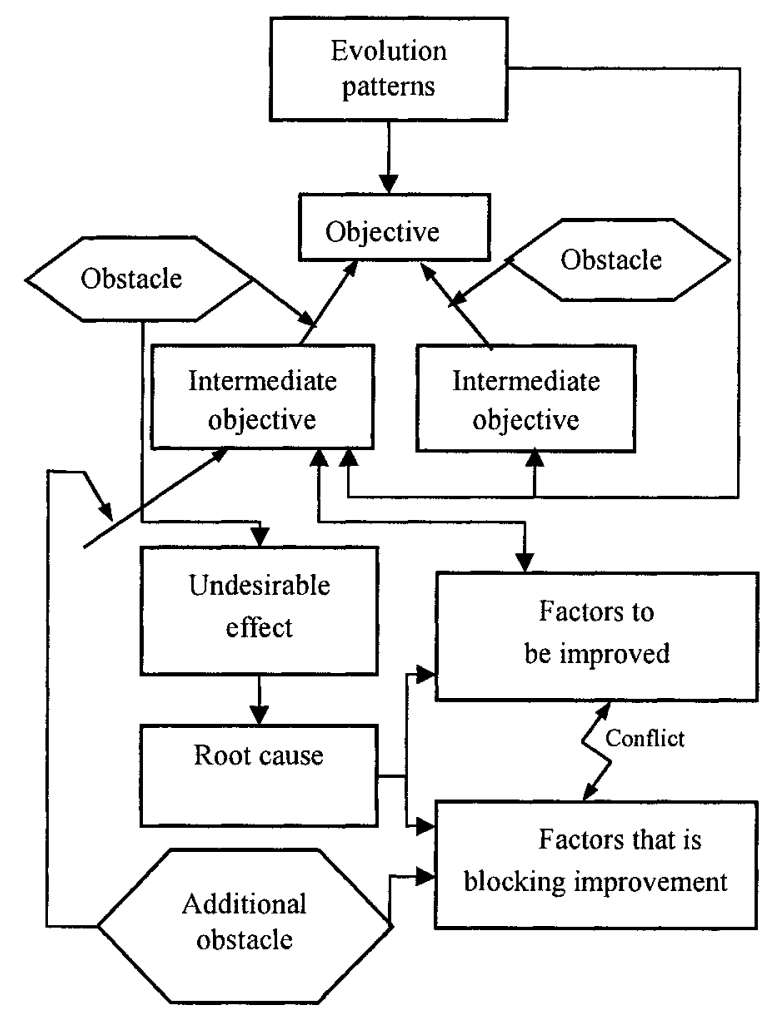

Figure 1. Contradiction identifying diagram

Step 1 Set up objective using evolution patterns of TRIZ. Because the result of evolution will cause the improvement of the performance or the parameter of product, the evolution objective can thus be determined directly.

Step 2 Build the Prerequisite Tree

List all the obstacles at first. Then, for each obstacle, identify a condition that overcomes the obstacle. This is usually a mutually exclusive condition, which implies the existence of contradiction.

By focusing on individual obstacles, we identify the smaller intermediate objectives (IOs) that lead us to our more ambitious goal.

Step 3 Identify contradictions through obstacles. A new conflict determining diagram is set up as shown in Figure 1. 
The determination of conflict can adopt the following template:

According to evolution objective, a useful function or a parameter will exist or be improved, but because of the existence of some obstacles, it won't exist or will cause the deterioration of other functions or parameters.

Physics conflict can be determined according to the template and conflict determining diagram directly.

When determining technical conflict, the improved parameter can be confirmed according to the template and conflict determining diagram. The worse parameter usually comes from an additional obstacle, which belongs to another subsystem. Converting them into 39 standard engineering parameters of TRIZ, the standardization of technical conflict is accomplished.

\subsection{Resolve design conflict}

For eliminating physical contradictions, four generic principles (separation principles) are used.

For technical contradictions, the 39 standard engineering parameters, contradiction matrix and 40 inventive principles in TRIZ should be used to solve them.

\section{ENGINEERING EXAMPLE}

Dropping pill is a rapidly developing form of Chinese traditional medicine. Dripping the mixture of liquid medicine into a cooling liquid under thermal condition, the process of pill formation results in a soliddispersoid in a pill shape $e^{15,16}$.

In the traditional machine, the dropping pills are acquired through the freedom dropping way. Because of the uncontrolled state, it is very difficult to keep the dropping pills dimensional uniformity during the dropping course. Figure 2 is the conflicts confirming procedure for the design of dropping pill machine. 


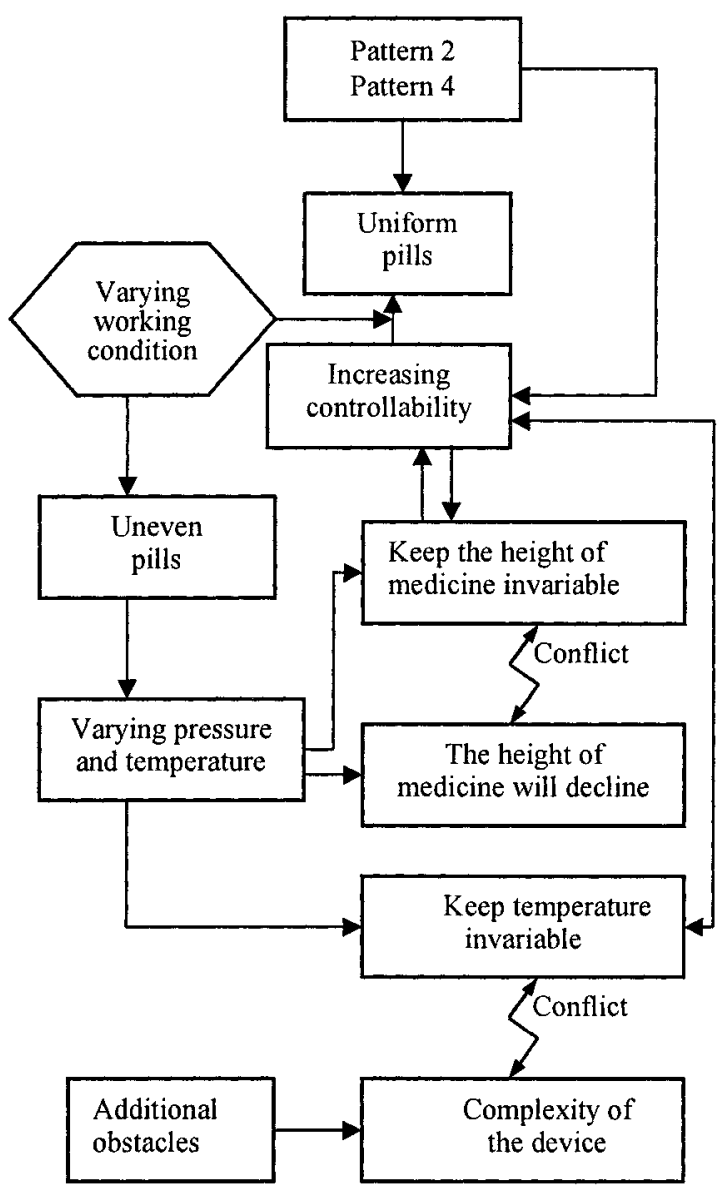

Figure 2. Confirm conflicts for design of dropping pill machine

Select pattern 2 and pattern 4 for the evolution direction of dropping pill machine, i.e., increasing ideality, dynamism and controllability. The ambitious goal, intermediate objective and obstacle can be determined. There are physical conflict and technical conflict as shown in Figure 2. For the physical conflict, the first generic principle can be applied and the corresponding inventive principles are No.9,No.10,No.11,No.15,No.16, No.18, No.19, No.20, No.21, No.29, No.34 and No.37. The usable inventive principles are No.11(Beforehand cushioning), No.15 (Dynamics) and No.29(Pneumatics and hydraulics).

The technical conflict can be expressed as the one between No.17 (Temperature) and No.36 (Complexity of a device) or No.38 (Level of 
automation) and No.36 (Complexity of a device) of the standard engineering parameters through standardization of technical conflict.

According to contradiction matrix of TRIZ, for the technical conflict between the standard engineering parameters No.17 and No.36 or No.38 and No.36, the corresponding inventive principles are No.2 (Extraction), No16 (Partial or excessive action) and No.17 (Another dimension) or No.10 (Prior action), No.15 (Dynamics) and No.24 (Mediator). No.2, No.10, No.15 and No. 24 can be adopted here.

Figure 3 is the design of dropping pill machine for Chinese traditional medicine.

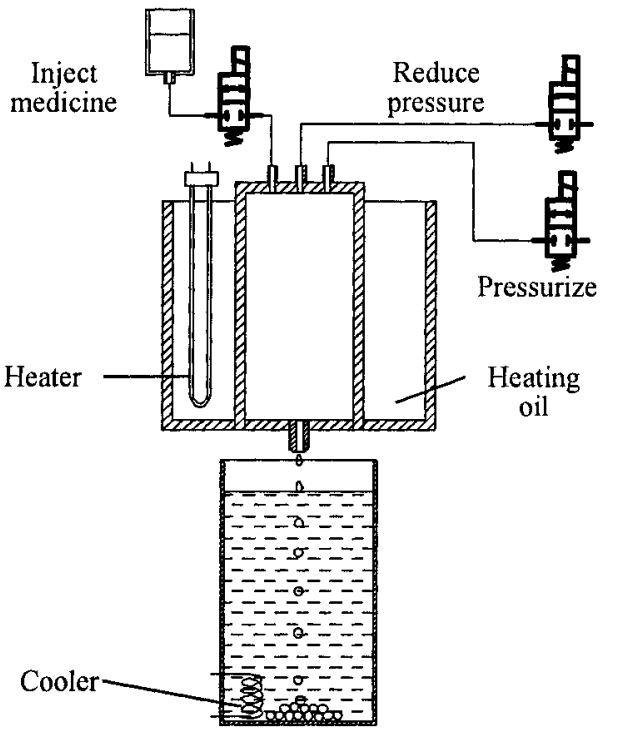

Figure 3. Innovation design of dropping pill machine

Before dropping, dropping nozzles are heated up by heating oil in advance. During dropping, the temperature of medicine can be fixed to stability constant by heating oil. The pressure of liquid medicine can be cushioned by compress air when it's falling. In this system, the dimensional uniformity of dropping pills can be kept. 


\section{CONCLUSIONS}

A determination model of design conflict based on the evolution theory of TRIZ and the Prerequisite Tree (PRT) is proposed, which can be used to identify physical and technical conflict. In this model, the evolution patterns are used to identify objectives and the PRT is used to identify all obstacles. Then the physical or technical contradiction can be found by the conflict determining flow and template. The separation principles or the conflict matrix in TRIZ are applied to solve them. The design example of dropping pill machine has verified the application of the process model.

\section{REFERENCES}

1. Kai Yang and Hongwei Zhang, A comparison of TRIZ and Axiomatic Design, TRIZ Journal (August, 2000); http://www.triz-journal.com.

2. Cavallucci D, Integrating Altshuller's development laws for technical systems into the design process, Annals of the CIRP, 2001, 50(1): pp.115-120.

3. Lee Noel, A new model of the conceptual design process using QFD/FA/TRIZ, TRIZ Journal, TRIZ 9 to Create the Ideal Product Design, http://www.triz-journal.com.

4. Terninko J, Selecting the best direction to create the ideal product design, TRIZ Journal, http//:www.triz-journal.com.

5. Runhua Tan et al., Study on the conceptual design process using QFD and TRIZ, Chinese Journal of Mechanical Design, Vol.9,pp. 1-4 (2002).

6. Ellen Domb, Finding the zones of conflict: tutorial, TRIZ Journal (June, 1997); http://www.triz-journal.com.

7. Runhua Tan, Theory of Inventive Problem Solving (Science Press, Beijing, China, 2004).

8. Eduardo C. Moura, TOC trees help TRIZ, TRIZ Journal (Sep, 1999); http:// www.trizjournal.com.

9. Ellen Domb and H.William Dettmer, Breakthrough innovation in conflict resolution marrying TRIZ and the Thinking Process, TRIZ Journal (May, 1999); http:// www.trizjournal.com.

10. Darrell Mann, Roy Stratton, Physical contradictions and evaporating clouds, TRIZ Journal (April, 2000); http:// www.triz-journal.com.

11. Semyon D. Savransky, Elementary Contradictions in TRIZ, International Conference on Engineering Design, ICED 99 MUNICH, August 24-26,1999.

12. Altshuller G, The Innovation Algorithm, TRIZ, Systematic Innovation and Technical Creativity, Technical Innovation Center, INC, Worcester, 1999.

13. Zusman A, Zlotin B, Zainiev G, An application of directed evolution, http://www.ideationtriz.com/Endoscopic_Case_Study.htm.

14. H.William.Dettmer, Goldratt's Theory of Constraints (ASQC Quality press, 1997).

15. Chunlin Cao, Chinese Medicine Pharmacy (Shanghai Science Press, China, 1999).

16. Zhaowang Zhang, Chinese Medicine Pharmacy (Chinese Medicine Press, China, 2003). 